\title{
Global Environmental Education: Towards a Way of Thinking and Acting*
}

\author{
by
}

\author{
WILliAM B. STAPP, PhD (Michigan) \\ Thurnau Professor of Environmental Education and Director of GREEN, \\ School of Natural Resources, University of Michigan, \\ Ann Arbor, Michigan 84104, USA, \\ $\&$ \\ Nicholas Polunin, DPhil., DSc(Oxon.), CBE \\ President of the World Council For The Biosphere and of the \\ Foundation for Environmental Conservation, Geneva, Switzerland.
}

\section{PREAMBLE}

It is almost a cliché to speak of the world as growing smaller each day. We tire of hearing the phrase; yet the deeper meaning of this concept frequently escapes us. Our interests have moved far beyond those of hereditary and cultural bonds, and far past telecommunications and transcontinental travel. This planet is no longer a delicate weave of beliefs, customs, patterns, and actions, but a seriously threatened one at least so far as being the oneand-only current habitat of our unique species, Homo sapiens, is concerned. Of this there can be no serious continuing doubt, though some of the worst threats are practically unrecognized or unpredictable, due to the greed or ignorance of that very species to which we all belong.

There is no longer any such thing as even local full independence. Each individual and nation is a part of this intricate but fragile weave. We are all linked geographically, historically, ecologically, economically, politically, religiously, socially, and in countless other ways. Viewing the world in this fashion, we see it as a tapestry of continuing, indeed at best ever-increasing, hope - a vision bound in unity, understanding, and ever-widening and deepening respect. There is no longer any question in our collective mind that the main 'villain of the piece' is our own, profligate species (Polunin, 1972, 1980; Polunin \& Burnett, 1990, in press).

Progress towards the solutions to complex problems and issues (such as world hunger, desertification, acidic precipitation, nuclear proliferation, and ultimate peace) is enhanced through cultural awareness and understanding, the international exchange of ideas and information, and actions that represent the outcome of holistic thinking. We need to see the world in its global context and, as educators, to assist citizens and legislators to act with a global perspective in mind and vision.

*The Authors wish to credit various globally-thinking educators and active institutions for many of the ideas brought forward in this paper; whereas most others are their own. The paper is based on the invited Keynote address of identical title given by Nicholas Polunin to the Consultation Meeting on the Use of Findings [of] Environmental Research to Environmental Education, held under the Auspices of UNESCO in the Foundation for International Studies of the University of Malta, Valletta, Malta, during 11-13 December 1989 - see the account in Environmental Conservation, Vol. 17, No. 1, pp. 86-7, 1990.
The most fundamental, most critical, knowledge that global environmental educators can impart is that all of us - Afghans, Americans, Australians, Chileans, Indians, Italians, Iranians, Kenyans, Russians, and all the way to Zulus - live together in a single human super-ecocomplex. We share common interests, common resources, and a common destiny. The result is a super-ecocomplex in which individual actions can have pervasive repercussions, yet a world in which we far-too-often act in ignorance of the countless impacts that we are, or may be, having practically all the time. Virtually no decision is simple: each morning cup of coffee affects coffee-bean growers in Brazil or elsewhere exotic; fertilizing lawns contributes to world hunger by limiting the capacity to produce crops in countries (mostly 'developing' or undeveloped nations) where soil quality is apt to be already poor; even each plastic bag in which we transport a purchase touches the world-wide demand for petroleum and weighs in the always tenuous balance that is somehow maintained between the oil-rich and oil-needy countries. North Americans, in particular, have a great effect on the world environment as they use an estimated $36 \%$ of its resources, yet house only $6 \%$ of its population. Thus the preponderant US Americans have an express responsibility to increase the world's sensitivity to global concerns, and always to remember that the oil will not last for ever.

Despite their increasingly widespread understanding of these facts, North Americans make many decisions that consider only how the outcome of the resulting activity will affect themselves, their immediate environment, or their particular state, province, or nation. It seems an urgent need that, to practically everyone everywhere, the world-wide implications of acidic precipitation, destruction of tropical rain-forests, and pollution of the oceans, should be made clear and so indicate the far-reaching economic, environmental, political, and social, impacts of their - and particularly US Americans' - daily choices. No political decisions, no long-standing national boundaries, and no laws, can well contain such repercussions. Yet, the linkages between these problems and peoples' own local actions frequently go unnoticed, being rarely comprehended with any proper degree of concern (Stapp, 1985; $c f$. Swann \& Stapp, 1974; Stapp \& Mitchell, 1991). 


\section{Personal-Level Decisions and Actions Can Affect THE GLOBE}

It is at the personal level that results can be most obvious, positive actions being felt directly at this level, and consequences being often most immediate. Though less apparent in the much wider context, local actions and personal decisions can and often do indeed have global ramifications as well. Collectively, our individual actions can surely have far-reaching effects, and so nurturing an understanding of this fact can develop within individuals a comprehensive view of the world environment while simultaneously establishing their own place, and responsibility, in helping to bring about solutions to current and foreseeable problems. Problem-solving is, then, by no means the sole realm of politicians and bureaucratic heads; community groups and individuals also have a fundamental, and often vital, role to play. By bringing situations to people's attention in a manner that illustrates how their own daily patterns may help to set off reactions around the world, they can become motivated to understand and act upon issues in a positive manner. This is a shared responsibility among all the world's human inhabitants that can best be ignited through effective global environmental education*.

\section{Need for Comprehensive Understanding of Our World}

With this in mind, a primary goal of education grows clear. At least in part through global environmental education, educators should help to foster in all people a comprehensive understanding of our only one Earth (Anon., 1987). We now have the opportunity to build a world of concerned people with the knowledge that local actions and personal decisions do indeed affect others very widely on our planet - either positively or negatively, and rarely quite neutrally — and that each individual therefore has a role in furthering solutions to environmental, political, and social, problems. Moreover there are occasions to remember chronic difficulties of supply meeting demand, with potentialities of grave shortages and famine always stalking on some horizon. Basically important is the need for people to develop the ability and inclination - indeed the urge - to act upon this knowledge and adopt a life-style that manifests this understanding, dedicated commitment, and concern for planet Earth as a whole. For it is our own and Nature's only practicable habitat, and beautiful in its integrated entirety when not disturbed by our profligate species.

With the need for such thinking so clear, and the stakes of failure so high, why is it that global perspectives are not better integrated into today's educational efforts? The answer is that the barriers to such integration and concomitant action are many and strong, and due understanding of holism's fundamental importance is barely beginning to sweep our prejudice-bound world.

In an address before the US National Association for Foreign Student Affairs, in Washington, DC, in May 1975, Dr Stephen K. Bailey ${ }^{\dagger}$ (1975) pointed out some significant facts that illustrate the results of these barriers

* At the worst it will be inculcated, in any humans that may survive, by some enormous global nuclear or other calamity. to effective global education in the United States, which we'll cite as one leading country with probably, nowadays, at least as much influence as any in the world. These data are now some sixteen years old, and current percentages are not available; but in most cases even optimistic growth-rates of 100 to $200 \%$ over the 1975 figures leave staggering deficiences:

- Only $3 \%$ of all undergraduate students - less than $1 \%$ of the college-aged group in the United States - have enrolled in any course which deals with international events or discusses foreign peoples and cultures in any way whatsoever.

- In 1973, a survey conducted by the American Association of Colleges of Teacher Education revealed that barely $5 \%$ of the teachers who were then being trained had any exposure at all to courses with international content or perspectives in their course-work for teacher certification.

- The current average newspaper coverage of international events which is read by the general public equals no more than one-half of one column of newsprint per day. Virtually none of the newspapers in the United States has foreign affairs reporters on the payroll. Fewer than twenty-four have any staff specialists in the area of foreign affairs.

- Notable imbalances characterize the nature and degree of expertise among international specialists in the United States. Here are some disquieting 'For instances': each of more than 100 million persons in the world speaks one of the following 'major' languages - Arabic, Bengali, Chinese, French, German, Hindi, Indonesian, Japanese, Portuguese, Russian, Spanish, Swahili, and Urdu. Yet the number of Americans who are expertly trained in one of at least half of those languages is fewer than 50 , while Middle Eastern language enrolments in the US draws a total of only about 1,300 per year. Even worse, all but a handful of these students drop out before they become truly proficient in the language they had been studying.

- Television coverage of world affairs in the US is largely episodic, dramatic, and transient; however, impressive exceptions must be acknowledged. ${ }^{* *}$

The barriers to bridging these gaps and helping individuals to develop a unified vision of the world environment occur pervasively. One obstacle lies in the tendency of education efforts in all arenas to emphasize differences rather than similarities. Many social-studies programmes in the US, that currently exist in all gradelevels, for instance, deal pointedly with the ways in which other cultures differ from the American. Through community groups, media, news reporting, schools, colleges, and universities, Americans teach primarily of 'our' resources and 'their' resources, though this situ-

$\dagger$ Vice-President and Director, International Education Project, American Council on Education.

** As this and the above four points or groups of points refer to situations that prevailed some sixteen years ago in a latterly fastchanging world, it would be interesting to have an updating soon - suspecting, as we do, that substantial improvements have taken place especially of late. - Ed. 
ation does not seem to be so limited in other Englishspeaking countries. American materials often lack a sense of world-oneness. As a result, American educators do not often stress connections, commonalities, and mutual respect. Rather, they promote a feeling of separation, though in the wider spheres of the former British Empire the situation seems to be generally much better.

\section{Notable Exceptions of Global Viewpoint}

Many notable exceptions to the above continentality do, however, emphasize the interdependence of world resources and the societies which need and use them, and it is such programmes that aid educators in incorporating a global perspective into their efforts. For example in Great Britain, with the United Kingdom's long practice of colonialism, which was often benevolent but not always so, there is widely a gratifying tendency to understand 'the other fellow's' viewpoint, while in much of Europe, for often comparable reasons, there prevails a tendency to a global viewpoint which is sometimes practically holistic.

Other constraints to adopting a global viewpoint are not so easily recognized. They tend to be of cultural, political, or social, derivation, and present deep-rooted obstacles that sometimes seem insurmountable. However, they can all be overcome with conscious and persistent effort, and could give place even to holism.

Conceptual lag* is a quiet but influential force in carrying on traditional ideas and delaying the incorporation of new thoughts into a common frame of reference. Ideas and values are moulded by past experience, and actions follow accordingly. Compounding this lag is the perpetuation of these deeply-imbedded values through inherent reinforcement by government, schools, and other social institutions. It therefore takes time for the united views that are promoted by global environmental education to catch on, and even longer for individuals to change their daily patterns to reflect this overdue growth.

Some political attitudes that have become prevalent in recent decades should be cited among the constraints to ready incorporation of a world-oriented outlook into modern educational systems. As a region, North America appears to be caught up in its own world; its natives seem to strive for short-sighted independence on a planet that is comprised - as explained and emphasized above of intricate linkages. Though an aggregation of widely compassionate peoples, and a region that is willing to give generously in the name of humanity, it is often difficult for North Americans to look beyond their own boundaries with a continual interest or concern for people and places beyond their immediate (though already wide) boundaries. This is partly due to North Americans' physical separation from most other regions of the world, and partly to their inherent wealth of generally sufficient resources. Some seeming self-sufficiency may also prevail in other parts of the world, and militate against a global and even holistic viewpoint and concomitant practice.

* In the sense of slowness to absorb new concepts or practices, often as a result of lack of encouragement or apparent barriers or restraints.

\section{Global Issues Should be the Ultimate Crux and Holistic} Practice the Means

Political ideologies, language differences, and a quest for power over others, often lead people to put local and national interests above global issues. We are understandably concerned with the protection and promotion of our own country's interests, and this is generally right so long as it does not conflict seriously with global outcomes. However, national pride can also impede our view of our role as a global influence, whether major or minor. The mistaken equation of nationalism with regionalism may hamper the move towards global environmental education. There is now much evidence of increasing acceptance of cultural and political ideologies other than individual nations' own, and a greater and ever-widening understanding of the singularity of the world; but there is need for continuing growth in these areas. So everything we can do to promote and consolidate such growth should be done, at whatever cost of effort - unfortunately few of us have any financial wherewithal.

A general feeling of egocentrism in modern cultures further bars ready acceptance of global perspectives in that it has created a concern for the immediate and the tangible. Environmental consequences, in particular, do not usually meet this description. It would be far easier and more effective to make environmentally sound decisions if the probable effects were known at the time a choice is made. But, more often than not, it takes many years for slow-building consequences to reach visible proportions in these respects. All too commonly, much damage is done long before there is any concrete evidence of how and why, or there is a sufficient build-up of knowledge of how to avoid it. It is difficult, too, to base decisions on impacts that will only be felt half-aworld away.

In the United States, people are fortunate to be living in a geographic region that is resource-rich, but this makes it more difficult for Americans to imagine the strains of nations that simply do not have their good fortune. Although such a problem as the destruction of tropical rain-forests is very real, and does indeed impact on Americans' own lives through the lives and products of others, it is easy for them to overlook this problem, as they commonly do not realize its ultimate effects or at least not its extreme gravity. Thus, it is essential that all good people find ways of illustrating their connections to these situations, of bringing them closer to home - both in terms of how their actions cause such problems, and of how they even affect their own lives.

\section{Overcome the Barriers}

Barriers such as the above are deeply rooted and difficult to master. Overcoming them is a large, at times seemingly insurmountable, task; but building a global perspective into virtually all existing daily patterns is an essential part of refuelling our spirits and finding solutions to world problems. Slowly, changes in attitudes are being cultivated. An increased sensitivity to other countries and their needs, facilitated in part by faster and cheaper intercontinental travel, cultural exchange programmes in schools as well as between nations, and a 
growing interest in tracing heritages, is creating a more and more culturally-bound globe. Educational efforts are multiplying their foci and expanding their range; we are beginning to recognize the common resources and common needs that tie us all together.

The strategies for breaking down the well-built and often strongly prejudiced obstacles to global environmental education are varied. Changing university requirements to include an emphasis on current world affairs rather than on ancient history, past languages, and extinct cultures; integrating international information and perspectives into existing courses; increasing modernlanguage requirements in schools and universities; and stressing similarities between people in all countries at every available opportunity; these are but a few of the ways of generating increased respect and understanding for the interconnectedness of the planet, enabling people to act on that knowledge, and generally considering our only one Earth holistically, with concomitant action on everybody's part.

\section{CRUCiAl IMPORTANCE OF GLOBAL ENVIRONMENTAL EDUCATION}

Much is occurring internationally to promote global environmental education, though never enough ( $c f$. Stapp, 1985). United Nations conferences on a wide range of topics such as desertification, population, energy, pesticides, and resources development, are acknowledging the importance of education as a basic part of finding solutions to world environmental problems. Also, over the past decade and more, an effective series of regional meetings sponsored by UNESCO and the United Nations Environment Programme (UNESCO-UNEP, 1975-83) have focused directly on the development of world-wide strategies and action programmes designed to further environmental education in all sectors of the world. There have also been 'private' events such as the series of International Conferences on Environmental Future (Polunin, 1972, 1980; Polunin \& Burnett, 1990, in press) and numerous regional and national symposia and seminars - all, either directly or indirectly, militating in the same general direction.

These programmes are making invaluable contributions to the growth of global perspectives in environmental education, and already are beginning to bring about significant changes in the quality of the world environment. However, they are apt to operate on such a very wide scale as to appear irrelevant to the vast majority of individuals. It is the task of the global environmental educator to find ways and means of scaling such ideas to a level that is tangible to each and every educated citizen of the world, due coordination of such much-needed efforts being activated it is ardentlyto-be-hoped by a rejuvenated International Society for Environmental Education (ISEE).

\section{Link Local to Global Implications and Imperatives}

One of the most significant strategies for bringing this about lies in linking personal, local actions to their positive and negative global implications. Dissecting the overwhelming issues which face our world today, with its far-too-many profligate humans, and bringing these issues to a level that has direct pertinence to the individual, is a potentially powerful method of nurturing a global environmental ethic in each person. Helping people to realize that their own actions compound to create or counter global problems, can only accelerate the latters' solutions, even as indicating an individual's personal part should increase his or her interest and concomitant keenness.

An important component of increasing our awareness of linkages between local actions and global impacts would be to obtain widespread agreement on the desirability of having some underlying aspects of cultural oneness throughout the world, and then campaigning for it successfully. Looking at the subcultures that exist within our own countries could be a useful prelude to this.* Educators should take advantage of the educational potential of their own city's or settlement's ethnicity through such means as festivals, dances, restaurants, interviews, and guest speakers - to help people to develop an acceptance of perspectives and practices that differ from their own.

Almost every area of our lives can be linked in some way to global effects; the repercussions of virtually every decision may be felt world-wide, and not necessarily on the smallest of scales. Our food-choices, for instance, have implications of universal concern: fresh produce saves resources (energy and otherwise) that go into processing and packaging canned or frozen fruits and vegetables. Locally-grown produce does not require the incredible amounts of fuel and other energy-sources that are devoted nowadays too commonly to cross-country or trans-ocean and international shipments; production and distinction of vegetarian sources of protein (beans and nuts) generally use-up only one-third of the energy that is required to raise and market beef-cattle. Our food purchases, therefore, are intricately tied to the world's energy supplies, however uncertain these may be. Each individual can contribute, albeit at a minuscule level, to energy conservation by making informed food-choices and so supporting environmentally sound concepts.

\section{Bad Example of North American Car Industry}

Similar, but often larger, repercussions can result from decisions which we make regarding transportation. The United States is by far the most car-dependent nation in the world, and the automobile industry is certainly a significant portion of their economy. The 'globalness' of the industry, though, is often overlooked: the dependence on raw materials imported from five continents to produce a single automobile; how local transportation decisions (big car, small car, bus, or bicycle) will impact on the global environment (emissions, fuel demands, resource use); how transportation patterns in other parts of the world are structured on a much broader base than

\footnotetext{
* Meanwhile a much-respected Referee has pointed out (in litt.) that 'The world is made up of $\mathbf{1} 77$ [nation-]states, comprising more than 17,000 ethnics or "nations" which treasure their differences in language, religion, homeland, myths of common descent, even phenotypes. On this subject [R. Paul Shaw's] book Genetic Seeds of Warfare is quite clear.'. - Ed.
} 
that of the US; and ways in which other countries cope with transportation problems that Americans are now facing. There is much indeed to be learned from looking beyond the United States' boundaries for solutions to a problem that directly impacts on American residents. Yet the latters' focus on national self-sufficiency too often limits the degree to which North Americans seek to learn from other, often more experienced, nations.

Daily decisions regarding solid waste, such as recycling the morning newspaper rather than throwing it into a trash-can, or re-using a lunch bag several times, or making a tube of shaving-cream last for more than two years as one of us has done quite painlessly, can bring about ultimately significant resource savings. Reducing, reusing, and recycling, can greatly influence global supplies of a very wide variety of natural resources. Fuel-use, too, can be substantially reduced by the compounded actions of people who put on sweaters rather than turning up the thermostat, and who wash only full loads of dishes or clothes. And psychologically it is ultimately important for the world, and not at all mean on the part of the individual, to be recognized as thrifty in such respects.

Housing, utilities, lawn-care, recreation - all of these, and many more, are areas in which we make personal decisions that have unnoticed but far-reaching effects. With global environmental education - and, more specifically, learning to think globally while acting locally - we can begin to account for our impacts on the world environment, which have been widely deplorable and even disastrous especially in the recent past. As people - individuals in every nation - learn to consider the implications of their actions for the rest of the world as well as for their own homes, and, as intelligent and concerned beings, to act accordingly, progress can be made towards a far more secure and environmentally sound planet than the one we currently inhabit.

\section{CONCLUSION}

We no longer have the option of foregoing a global perspective; there is unquestionably dire need for widelyincreased global environmental education towards increased respect for the world environment. Educators - in schools and out of schools - can more effectively prepare the world citizenry to understand, live with, and act responsibly upon, the crucial truth of the oneness of the world. The 'haves' must learn that there are 'havenots', and realize that the resentment and bitterness which the latter can bear is perhaps justified. We must all learn that world security thus depends literally on building due respect for all nations and cultures, and that people the world over have rights to reasonable complements of acceptance, peace, and human dignity.

Now let us add a final point for sad reflection and needed remedial action, especially by educators: practically all of the worst environmental dangers that beset our world - of threats to the all-important stratospheric ozone shield, of grave doubts about our food and fuel adequacy in the future, of human population pressures as the basic problem, of nuclear holocaust and attendant horrors, of the 'greenhouse effect' of build-up of atmospheric carbon dioxide, methane, etc., of ever- increasing deforestation and desertification, of eutrophication and more extreme pollution, of depletion of essential raw-materials, and more - were known and already debated at our first International Conference on Environmental Future, held in Finland in 1971, the year before the big United Nations Conference on the Human Environment at Stockholm. Consequently the publishers, Macmillan, were well justified in printing a huge red 'PRIORITY' across the dust-jacket of the fat book of proceedings, though it annoyed one of us as Editor at the time. Indeed, if these matters had been publicly perceived and widely guarded against by our species, Homo misnamed sapiens, at that now seemingly far-off time, our world would currently be in a far less unhappy state than it is. In an attempt to inculcate realization as widely as possible of the gravity of the situation, one of us gave an 'Around the World Talk' entitled 'Our World Menaced' a few years ago (Polunin, 1987) and has belaboured the subject ever since, believing confidently that global environmental Education could still be the key to our civilization's Salvation, even this late in our history.

Yet a further sobering realization is the speed with which still other menaces have emerged in the last two decades and even very few years - widespread acidic deposition and salinization, impending insufficiency of agricultural land inter alia with seemingly inevitable sealevel rises, major human epidemics such as AIDS, garbage and other wastes' disposal, over-dependence on modern machines and devices, and major climatic and possibly cosmic effects. Of all these grave matters, and doubtless others still to emerge, the world at large should be appraised, and that, it seems to us, is the responsibility primarily of educators - hopefully with the encouragement and support of governments and the media throughout the world, and remembering always that practically all of the problems are of our own making.

To us it seems clear that, to save The Biosphere and survive continuingly with it, strong leadership is called for through international and indeed global action which we feel could come from guidelines agreed to, and issued universally by, UNEP, IUCN, and some other world bodies. All of these and other efforts should converge on the need ultimately of the evolution of a pandominant race of Humankind, or at least the emergence of a global cult, that will consistently and unswervingly place the welfare of The Biosphere ahead of all personal or other partisan considerations.

\section{SUMMARY}

Our world of Mankind and Nature is becoming more and more seriously threatened as human populations and profligacy increase. Yet short of near-future calamity, there should be hope in global environmental education as a basis for countering such threats as those of world hunger, acidic precipitation, increasing desertification, nuclear proliferation, 'greenhouse' warming, and stratospheric ozone depletion. We need to educate people throughout the world to see these dangers in their global context and to act always within this perspective - be 
they decision-makers, legislators, or mere private citizens. For their actions and effects compound to make up those of their pandominant species, the likes of which our unique planet Earth can surely never have experienced before, and consequently its all-important Biosphere, constituting virtually the whole of our and Nature's lifesupport, is totally unprepared to withstand.

The above means that decisions and concomitant actions at the personal level can and often do affect the globe, to however infinitesimal a degree, and of this all people on Earth should be forewarned, acting on it with clear understanding and due responsibility. Particularly North Americans should realize that their effect is disproportionately large, as they use some $36 \%$ of the world's resources although comprising only about $6 \%$ of its population. Towards remedying such anomalies and effecting an improved sharing of responsibility among all the world's human inhabitants, an urgent need is, clearly, effective global environmental education. We need a world of concerned people with the knowledge that personal decisions and local actions can affect others very widely, and that each individual human being thus has a role in furthering solutions to environmental, as well as political and social problems.

With the need for such thinking and action so clear, and the stakes so very high, why is it that global perspectives are not better integrated into today's educational system? 'The answer is that the barriers to such integration and concomitant action are many and strong, and due understanding of holism's fundamental importance is barely beginning to sweep our prejudice-bound world.' These barriers include lack of student interest and pertinent enrolment, lack of international perspective among teachers and in the general press, and lack of television and other news-media coverage of such real world affairs. A general obstacle lies in the tendency of educational efforts to emphasize differences rather than similarities - scarcely conducive to fostering an interdependent, one-world ethic. Yet global issues should be our ultimate consideration, and holistic practice our means of furthering them for lasting survival.

It is clear that we humans no longer have the option of foregoing a global perspective, and that there is dire need for widely-increased global environmental education to inculcate greatly-increased respect and concern for the world environment. This is brought starkly to mind on realization that practically all the horrors which now beset our world were known fairly widely already twenty years ago - including threats to the stratospheric ozone shield, the 'greenhouse effect' on world climate, the effects of deforestation and devegetation with ever-increasing human population pressures, and many more - and that new ones keep on emerging. These latter include build-up of nuclear-waste and other pollutions, AIDS, everincreasing acidic deposition and salinization, flooding of lowlands and other effects of climatic changes, and further foreseeable problems that are likewise of our own making in being due to human overpopulation, ignorance, and/or profligacy.

\section{REFERENCES}

ANon. (1987). Our Common Future. (World Commission on Environment and Development report under Chairmanship of Dr Gro Harlem BRUNDTLAND.) Oxford University Press, Oxford, England, UK: xv +400 pp.

BAILEY, Stephen K. (1975). [Address delivered in circumstances indicated on page 14.]

PolunIN, Nicholas (Ed.) (1972). The Environmental Future: Proceedings of the first International Conference on Environmental Future, held in Finland from 27 June to $3 \mathrm{July}$ 1971. Macmillan, London \& Basingstoke, England, and Bames $\&$ Noble, New York, NY, USA: xiv + 660 pp., illustr.

Polunin, Nicholas (Ed.) (1980). Growth Without Ecodisasters? Proceedings of the Second International Conference on Environmental Future (2nd ICEF), held in Reykjavik, Iceland, 5-11 June 1977. Macmillan, London \& Basingstoke, England, UK, and Halsted Press Division of John Wiley \& Sons, New York, NY, USA: xxvi + 675 pp., illustr.

Polunin, Nicholas (1987). Around the World Talk (c. 35 minutes): Our World Menaced: Quebec City, Los Angeles, Seoul, Hong Kong, Singapore, Bahrain, Geneva. The Foundation for Environmental Conservation, Grand-Saconnex, Geneva, Switzerland: $7 \mathrm{pp}$. (mimeogr.).

POlunin, Nicholas \& BURNETT, Sir John H. (Eds) 1990). Maintenance of The Biosphere: Proceedings of the Third International Conference on Environmental Future (3rd ICEF) [held in Edinburgh, Scotland, UK, 24-26 September 1987]. Edinburgh University Press, 22 George Square, Edinburgh EH8 9LF, Scotland, UK: xvi +228 pp., illustr.

Polunin, Nicholas \& BurnetT, Sir John H. (Eds) (in press). Surviving With The Biosphere: Proceedings of the Fourth International Conference on Environmental Future (4th ICEF), held in Budapest, Hungary, during 22-27 April 1990. Edinburgh University Press, 22 George Square, Edinburgh EH8 9LF, Scotland, UK.

STAPP, William B. (1985). Guest Editorial: Some overall imperatives of the Environmental Education Movement. Environmental Conservation, 12(2), pp. 103-4.

STAPP, William B. \& MrTchell, Mark (1991). Field Manual of Water Quality Monitoring: An Environmental Education Program for Schools. Thomson-Shaw Publishers, Dexter, Michigan, USA: $225 \mathrm{pp}$.

SWAN, James A. \& STAPp, William B. (Eds) (1974). Environmental Education. Halsted Press Division of John Wiley \& Sons, New York-London-Sydney-Toronto: 349 pp., numerous figs \& tables.

UNESCO-UNEP (1975-83). Activities of UNESCO-UNEP International Environmental Education Programme (1975-83). UNESCO, Paris, France: ii +35 pp., mimeogr. 